\title{
Chemistry with Organophosphorus Syntheses in Focus
}

59(1), pp. 82-95, 2015

DOI: $10.3311 /$ PPch.7317

Creative Commons Attribution (i)

RESEARCH ARTICLE

\author{
György KEGLEVICH ${ }^{1 *}$, Alajos GRÜN¹, Péter BAGI ${ }^{1}$, Erika BÁLINT², \\ Nóra Zsuzsa KISS ${ }^{1}$, Rita KOVÁCS ${ }^{1}$, Erzsébet JABLONKAI ${ }^{1}$, \\ Tamara KOVÁCS ${ }^{1}$, Elemér FOGASSY ${ }^{1}$, István GREINER ${ }^{3}$
}

ReCEIVEd 30 January 2014; ACCEPTEd AFter REVISION 31 MARCH 2014

\begin{abstract}
The use of the microwave (MW) technique has many advantages in organophosphorus chemistry. MW irradiation may replace a catalyst, or simplify a catalytic system. New reactions may also become possible under MW irradiation. In most cases, microwaves just make the reactions more efficient in respect of rate, selectivity and yield. The benefits are shown via representative examples. In another field, our methods developed for the resolution of cyclic phosphine oxides and phosphinates are summarized. After deoxygenation, the racemic or optically active P-heterocycles were used as P-ligands in platinum complexes that together with other derivatives are potential catalysts. The third topic embraces the optimization of the synthesis of dronic acids/dronates. Starting from the corresponding carboxylic acids and using methanesulfonic acid as the solvent, 3 equivalents of phosphorus trichloride is enough as the P-reactant. Applying sulfolane as the solvent, the optimum set of reactants comprises 2 equivalents of phosphorus trichloride and phosphorous acid.
\end{abstract}

\section{Keywords}

organophosphorus chemistry, green chemistry, microwave, resolution, platinum complexes, dronic acids/dronates

\footnotetext{
${ }^{1}$ Department of Organic Chemistry and Technology, Faculty of Chemical Technology and Biotechnology, Budapest University of Technology and Economics, H-1521 Budapest, Hungary

${ }^{2}$ MTA-BME Organic Chemical Technology Research Group, H-1521 Budapest, Hungary

${ }^{3}$ Gedeon Richter Plc., 1475 Budapest, Hungary

"Corresponding author, e-mail: gkeglevich@mail.bme.hu
}

\section{Introduction}

In this minireview, our recent results in environmentallyfriendly ("green") chemistry have been summarized. In the first sub-chapter the usefulness of the microwave technique is shown in organophosphorus chemistry. The second sub-chapter summarizes our results on the resolution of cyclic phosphine oxides, as precursors for $P$-ligands and on the synthesis of platinum complexes as potential catalysts. Catalysts are of utmost importance from the point of view of green chemistry. The last sub-chapter comprises our experiences on the optimization of the synthesis of dronic acid derivatives that are important drugs against bone diseases.

\section{Microwave-Assisted Organophosphorus Synthesis}

1.1 The Potential of Microwave Irradiation

in Synthetic Organic Chemistry

The use of the microwave (MW) technique in organic syntheses spread fast in research laboratories, and after almost three decades it is close to gaining industrial applications [1]. These days, sophisticated MW equipment is available and utilized on a wide scale of syntheses, such as substitutions, acylations, esterifications, alkylations, $\mathrm{C}-\mathrm{C}$ coupling reactions, additions, eliminations, condensations, cycloadditions, rearrangements and the formation of heterocycles [2].

It is possible that a catalyst can be omitted or simplified under MW conditions. The most valuable benefit is when a reaction can be performed that is impossible on conventional heating. This may be the consequence of a so-called special MW effect [3]. The most common benefits from MW irradiation are the considerable shortening of the reaction times and the increase in the selectivity and yield. In this article, the advantages of the use of the MW technique are demonstrated within the discipline of organophosphorus chemistry. Organophosphorus compounds including $P$-heterocycles find applications in synthetic organic chemistry as reactants, solvents (ionic liquids), catalysts and $P$-ligands in catalysts, and, due to their biological activity, also as components of medicines and plant protecting agents [4-6]. The application of the MW technique in organophosphorus chemistry is a relatively new field [7-13]. 
In this subchapter, the advantages of the application of the MW irradiation are shown via selected examples.

\subsection{Reactions in which the Catalysts are Replaced or Simplified by MW Irradiation}

We found that simple $\mathrm{CH}$-acidic compounds underwent a liquid-solid phase $\mathrm{C}$-alkylation by reaction with alkyl halides in the presence of $\mathrm{K}_{2} \mathrm{CO}_{3}$ under solvent-free $\mathrm{MW}$-assisted conditions. It means that the phase transfer catalyst could be substituted by MW irradiation [14,15]. This method was then extended to the alkylation of tetraethyl methylenebisphosphonate (1a), diethyl cyanomethylphosphonate (1b) and triethyl phosphonoacetate (1c) to afford the corresponding monoalkylated products (2a-c) in variable yields (Scheme 1) [16-18].

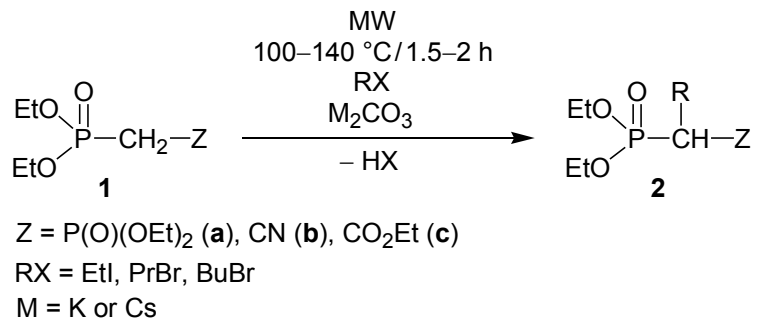

Scheme 1

The dialkylation of $\mathrm{CH}$-acidic compounds were also elaborated under similar, but more forcing conditions [19].

In another field, valuable $\alpha$-aminophosphonates (3A) [20] and $\alpha$-aminophosphine oxides (3B) were synthesized by the solventand catalyst-free MW-assisted Kabachnik-Fields condensation of primary amines, aldehydes/ketones and $>\mathrm{P}(\mathrm{O}) \mathrm{H}$ species (Scheme 2) [21]. In earlier syntheses, special catalysts (e.g. $\mathrm{BiNO}_{3}$ [22], phthalocyanine [23], lanthanoid(OTf) ${ }_{3}$ [24], magnesium perchlorate [25] and gallium(III) iodide [26]) were applied that cannot be regarded environmentally friendly species. We proved that under MW conditions there was no need for any catalyst. It was also found that the syntheses can be carried out without the use of any solvent [27].

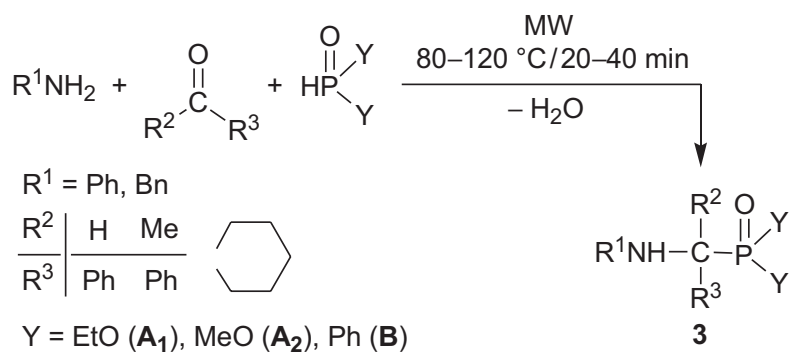

Scheme 2

Applying heterocyclic amines or $>\mathrm{P}(\mathrm{O}) \mathrm{H}$ species, the $\alpha$-aminophosphonates and $\alpha$-aminophosphine oxides synthesized included $N$-heterocyclic [28] and $P$-heterocyclic derivatives [29].
A few $N$-(2H-pyranonyl)- $\alpha$-aminophosphonates or $-\alpha$-aminophosphine oxides were also synthesized starting from 3-amino-2 $H$-pyran-2-one derivatives [30,31].

Double "phospha-Mannich" condensations were also developed applying two equivalents of the formaldehyde and the $>\mathrm{P}(\mathrm{O}) \mathrm{H}$ species to one equivalent of the primary amine (Scheme 3) [32-34].

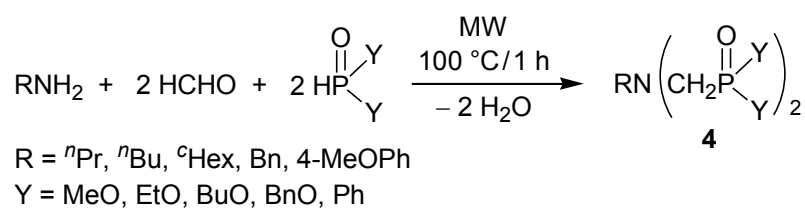

Scheme 3

The bis(phosphinoxidomethyl)amines (4, $\mathrm{Y}=\mathrm{Ph}$ ) were useful precursors of bidentate $P$-ligands after double deoxygenation that could be used for the synthesis of ring platinum complexes [32-34]. (More details in Subchapter 2.2)

The Hirao reaction is the coupling of aryl halides and dialkyl phosphites in the presence of $\mathrm{Pd}\left(\mathrm{PPh}_{3}\right)_{4}$ and triethylamine. Many variations were elaborated in the last two decades $[35,36]$. It is noteworthy that the Pd-catalyzed reaction took place efficiently in the presence of $\mathrm{Pd}(\mathrm{OAc})_{2}$ without any ligand on MW irradiation (Scheme 4) [37]. The corresponding products (5) were formed in high yields (73-95\%). This is the first case for the $P$-ligand-free accomplishment of the Hirao reaction.

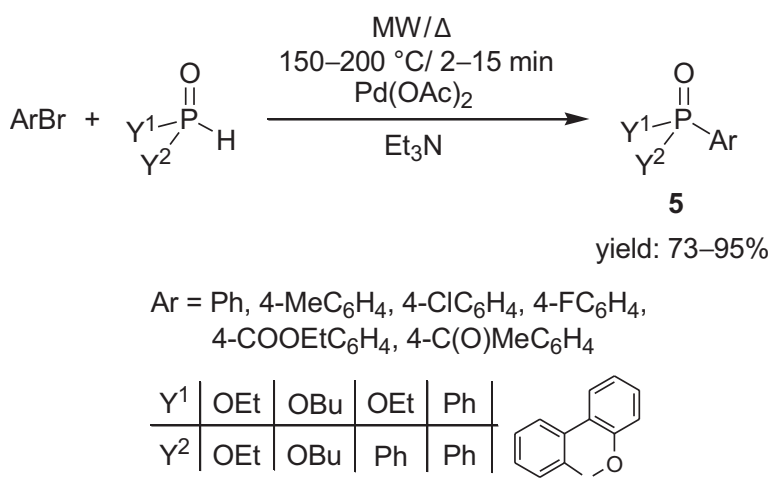

Scheme 4

Arylphosphonates $\left(\mathbf{5}, \mathrm{Y}^{1}=\mathrm{Y}^{2}=\right.$ alkoxy) may also be obtained by the MW-assisted Arbuzov reaction of aryl bromides and trialkyl phosphites [38].

We also found that in the O-alkylation of phenols, the MW irradiation and the phase transfer catalyst synergized each other $[39,40]$. Quaternary ammonium salts served as special alkylating agents [41]. In the MW-assisted O-alkylation of phosphinic acid, the use of a phase transfer catalyst was useful, when alkyl halides of normal or decreased reactivity were used $[42,43]$. 


\subsection{Reactions Otherwise Very Slow or Impossible Under Thermal Conditions}

The use of the MW technique was useful in the inverse Wittig-type reaction of 2,4,6-triisopropylphenyl-3-phospholene oxides, -phospholane oxides and -1,2- dihydrophosphinine oxides (all marked by $\mathbf{6}$ ) and dimethyl acetylenedicarboxylate to provide $\beta$-oxophosporanes 7. Completion under thermal conditions required a $c a$. 2 week's heating at $150{ }^{\circ} \mathrm{C}$. At the same time, on MW irradiation, the reaction was complete already after $3 \mathrm{~h}$ at the same temperature. No solvent was used in either case (Scheme 5) [44,45].

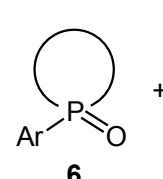

6

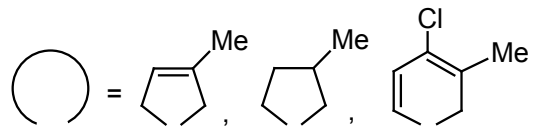

$\mathrm{Ar}=2,4,6-$ tri- $^{i} \mathrm{PrPh}$

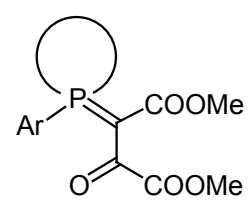

$7(80-92 \%)$
Scheme 5

With 2,4,6-triethylphenyl substituent, the reaction took place only on MW irradiation [44].

It is well-known that phosphinic acids (8) do not undergo direct esterification with alcohols to give phosphinates (9) (Scheme 6/A). For this, the esters of phosphinic acids (9) are usually prepared by the reaction of phosphinic chlorides (10) with alcohols in the presence of a base (Scheme 6/B) [4]. Another possibility is the synthesis by the Arbuzov reaction (Scheme 6/C) [4].

The esterification method in use (Scheme 6/B) has the drawback of using relatively expensive $P$-chlorides (e.g. 10). Besides this, the hydrogen chloride formed as the by-product has to be bound by a base. Consequently, the method is not atomic efficient and is not environmentally-friendly.

We were successful in the direct esterification of phosphinic acids with alcohols used in a $c a$. 15-fold excess under MW conditions. A series of phosphinic acids underwent efficient esterification using alcohols with longer chain at around $200^{\circ} \mathrm{C}$ on MW irradiation (Scheme 7) [43, 46-48].
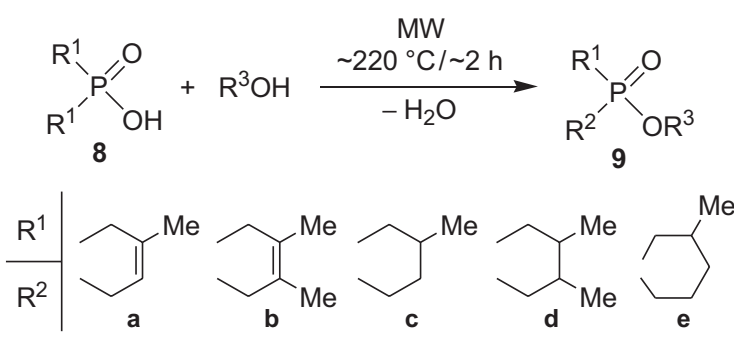

$\mathrm{R}^{3}={ }^{n} \mathrm{Bu},{ }^{n}$ Pent, ${ }^{\text {PPent, }}{ }^{n}$ Oct, ${ }^{i}$ Oct, Dodecil

Scheme 7

The esterification of cyclic phosphinic acids, such as 1-hydroxy-3-phospholene oxides (8a and $\mathbf{8 b}$ ), 1-hydroxyphospholane oxides (8c and 8d) and 1-hydroxy-1,2,3,4,5,6hexahydrophosphinine oxide $(\mathbf{8 e})$ was carried out in a closed vessel to afford the phosphinates (9a-e) in acceptable to excellent yields $[43,46-48]$. The method elaborated by us is of a more general value. It was also found that the esterification of phosphinic acids is thermoneutral, and controlled kinetically [47].

The esterification of 1-hydroxy-3-methyl-3-phospholene oxide (8a) was also attempted with thiobutanol. In this case, the thiobutoxy-phospholene oxide (10) was obtained in a yield of $38 \%$. No butoxy-product $9 \mathbf{a}\left(\mathrm{R}^{3}={ }^{\mathrm{n}} \mathrm{Bu}\right)$ was formed (Scheme 8) [49].
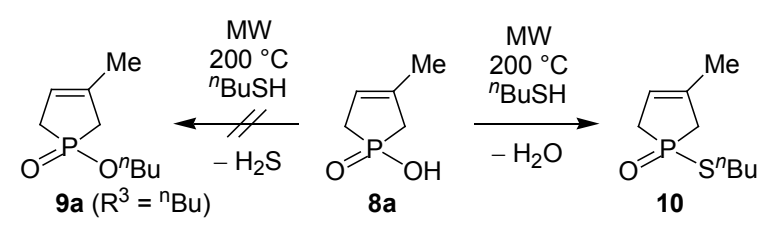

Scheme 8

The outcome of the reaction confirmed that indeed the alcohol is phosphinoylated and that the phosphinic acid is not alkylated. The conversion was, however, moderate which was in accord with the results of the quantum chemical calculations. It was found that the thioesterification is rather endothermic $\left(48.5 \mathrm{~kJ} \mathrm{~mol}^{-1}\right)$, and the enthalpy of activation is higher $\left(145 \mathrm{~kJ} \mathrm{~mol}^{-1}\right)$, than that for the reaction with butanol $\left(102 \mathrm{~kJ} \mathrm{~mol}^{-1}\right)$ [49]. Hence, the incomplete conversion even under MW conditions is justified.

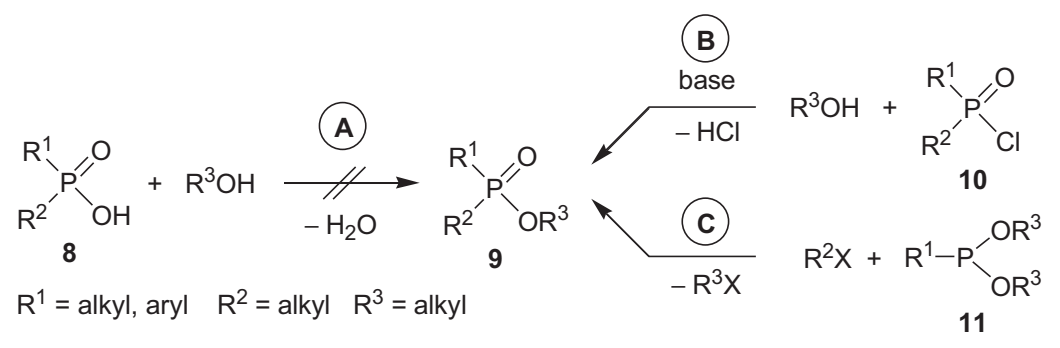

Scheme 6 
It seemed to be also interesting to attempt the MW-assisted direct amidations of 1-hydroxy-3-methyl-3-phospholene oxide (8a). Using hexylamines and benzylamine at $220{ }^{\circ} \mathrm{C}$, the amidations took place in rather low (ca. 33\%) conversions [50]. We had to return to the old method synthesizing the cyclic phosphinic amides (12) via the corresponding phosphinic chloride (11) as the intermediate. In this way, the amides (12) were obtained in yields of $c a$. 80\% (Scheme 9) [51].

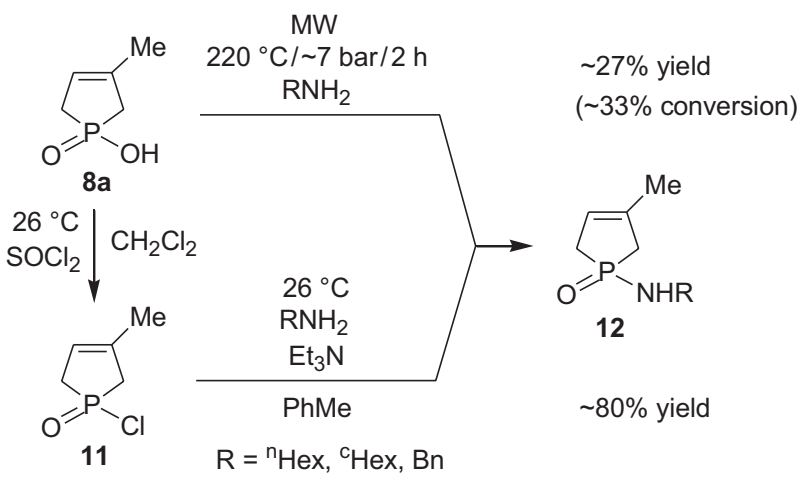

Scheme 9

\subsection{Reactions that Became More Efficient Under MW Conditions}

There are a lot of reactions within organophosphorus chemistry that became more efficient on MW irradiation [7]. The advantages include faster and more selective reactions. Besides this, in most of the cases, there is no need for solvents. Such reactions include, for example, Diels-Alder cycloadditions [52], fragmentation-related phosphorylations [53] and Arbuzov reactions as shown above in Subchapter 1.2 [38].

The MW-assisted synthesis of $\alpha$-hydroxyphosphonates (13) from substituted arylaldehydes and dialkyl phosphites under solventless conditions may be another example (Scheme 10) [54].

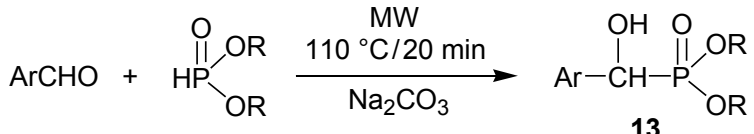

$\mathrm{Ar}=\mathrm{Ph}, 4-\mathrm{MeOC}_{6} \mathrm{H}_{4}, 4-\mathrm{MeC}_{6} \mathrm{H}_{4}, 4-\mathrm{ClC}_{6} \mathrm{H}_{4}, 4-\mathrm{NO}_{2} \mathrm{C}_{6} \mathrm{H}_{4}$ $\mathrm{R}=\mathrm{Et}, \mathrm{Me}$
In another variation, the dialkyl phosphites were added onto the carbonyl group of $\alpha$-ketophosphonates (14). In the reaction of acetylphosphonates $\left(\mathbf{1 4}, \mathrm{R}^{1}=\mathrm{Me}\right)$, the target hydroxy-methylenebisphosphonates (15) were obtained selectively under MW conditions. However, in the reaction of benzoylphosphonates $\left(14, \mathrm{R}^{1}=\mathrm{Ph}\right)$, the formation of mixed phosphonates-phosphates (16) was inevitable as a result of a rearrangement (Scheme 11) [55,56].

The hydroxy-methylenebisphosphonates are analogues of dronic acids/dronates which are used widely in the treatment of bone diseases [57]. See Subchapter 3.

In summary, the MW technique was shown to have an increasing potential in organophosphorus chemistry. In certain instances, MW irradiation may substitute catalysts. In other cases, it may make possible otherwise impossible transformations, or, as in most cases, simply promotes the reactions.

\section{The Resolution of Cyclic Phosphine Oxides and the Synthesis of Platinum-Phosphine Complexes}

\subsection{Resolution of the Optical Isomers of Cyclic} Phosphine Oxides

The preparation of $P$-chiral phosphines in enantiopure form is of great interest, as the transition metal complexes of these P(III)ligands may be applied as enantioselective catalysts in various homogeneous catalytic reactions. A well-established route for the preparation of the optically active $P$-chiral phosphines is the resolution of the racemic phosphine oxides followed by deoxygenation taking place, in most of the cases, by retention [58,59].

In recent years, efficient resolution methods for 5- and 6-membered $P$-heterocycles, such as 1-aryl-, 1-alkyl- and 1-alkoxy-3-phospholene oxides (17), 1-phenyl-3-phospholene sulfide (18), 3-phenyl-3-phosphabicyclo[3.1.0]hexane 3-oxide (19), 1-phenyl-1,2-dihydrophosphinine oxide (20) and 1-phenyl1,2,3,6-tetrahydrophosphinine oxide (21) were elaborated in our research group using TADDOL derivatives (22 and 23) [60-66], as well as the $\mathrm{Ca}^{2+}$ salts of $O, O^{\prime}$-dibenzoyl- and $O, O^{\prime}$-di-ptoluoyl-(2R,3R)-tartaric acid (24 and $\mathbf{2 5})$ as resolving agents [6775]. The resolution of the 5- and 6-membered $P$-heterocycles (17-21) was possible using TADDOL derivatives (22 and 23) via the formation of diastereomeric molecular complexes.

Scheme 10

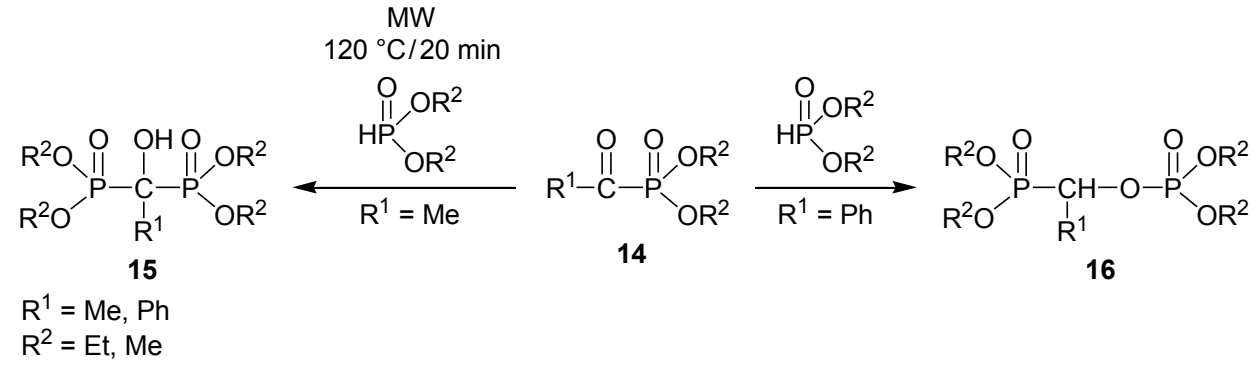

Scheme 11 

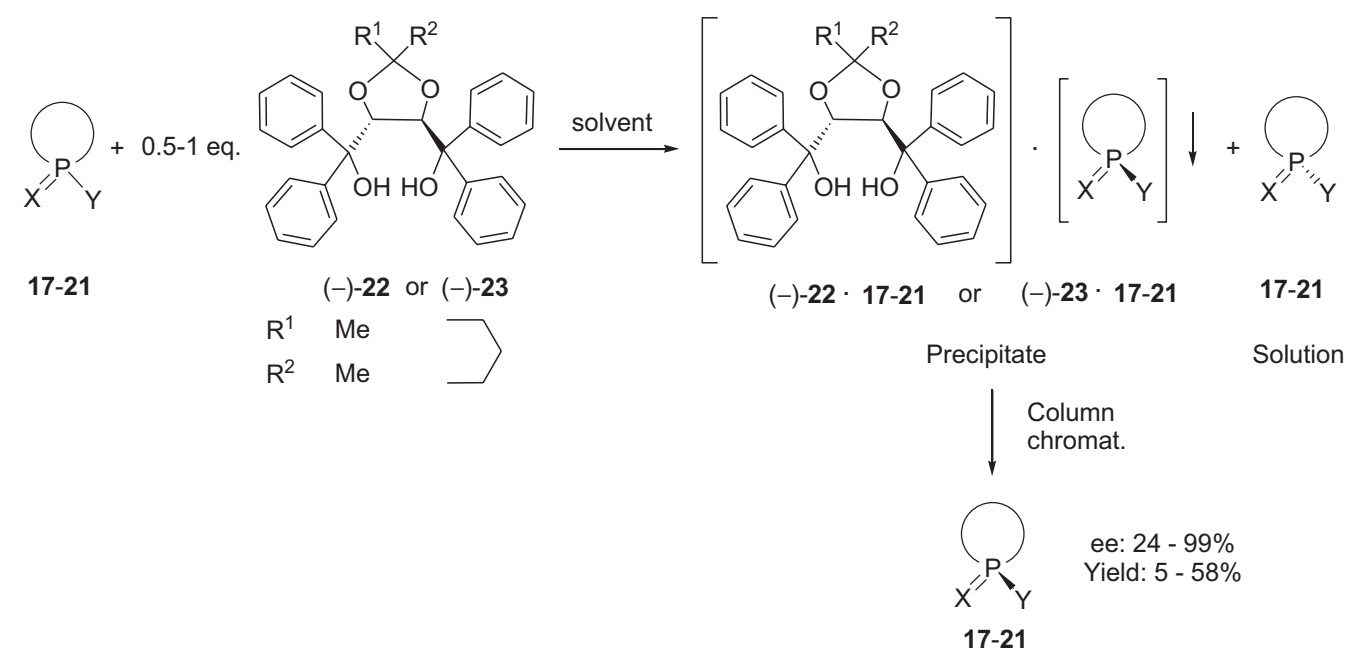

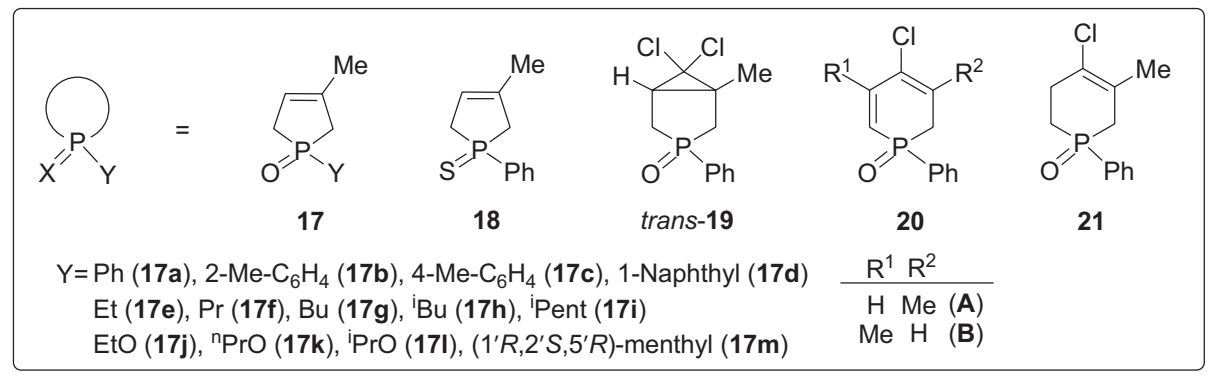

Scheme 12

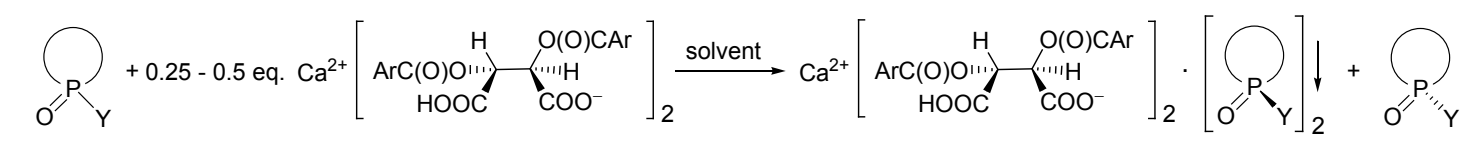

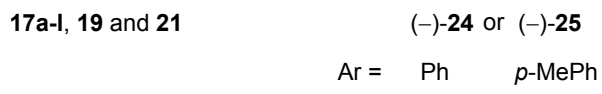

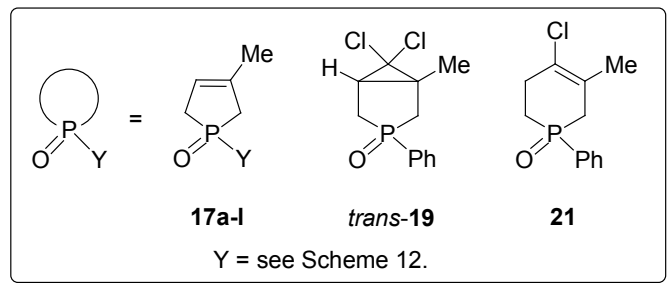

$(-)-24 \cdot 17 \mathrm{a}-\mathrm{I} \quad$ or $\quad(-)-25 \cdot 17 \mathrm{a}-\mathrm{I} \quad 17 \mathrm{a}-\mathrm{I}, 19$ and 21

$(-)-24 \cdot 19 \quad(-)-25 \cdot 19$

$(-)-25 \cdot 21$

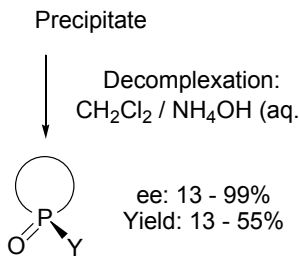

17a-I, 19 and 21

Scheme 13

The diastereomers were purified by recrystallizations, and the $P$-heterocycles (17-21) were recovered by column chromatography (Scheme 12) [60-66,70-75]. In most instances, the resolutions were carried out in a mixture of ethyl acetate and hexane $[60,61]$, but alcohols were also suitable solvents [63,73-75]. Moreover, the replacement of ethyl acetate by other solvents influenced the efficiency of the resolutions, as well as the nature of the enantiomer incorporated in the diastereomer formed during the resolution of 3-phosphole oxides (17). This phenomenon allowed us to develop resolution procedures for both enantiomers of the 3-phosphole oxides (17) from the racemic compounds $[63,74,75]$.

Besides the TADDOL derivatives, the acidic $\mathrm{Ca}^{2+}$ salts of $O, O$ '-dibenzoyl- and $O, O^{\prime}$-di- $p$-toluoyl-(2R,3R)-tartaric acid (24-25) were also suitable resolving agents for the separation of the enantiomers of 3-phospholene oxides (17), 3-phenyl-3phosphabicyclo[3.1.0] hexane 3-oxide (19), and 1-phenyl-1,2,3,6tetrahydrophosphinine oxide (21). In these cases, the separation of the enantiomers was accomplished via the formation of diastereomeric coordination complexes (Scheme 13). The diastereomers obtained were purified by digestion (i.e. by stirring the crystalline diastereomers at the appropriate temperature in the given solvent), and the enantiomers or enantiomeric mixtures of the 5- or 6-membered $P$-heterocycles (17a-1, 19 or 21) were recovered by treating the dichloromethane solution of the diastereomeric coordination complexes with aqueous ammonia [67-69,71-75].

The neutral $\mathrm{Ca}^{2+}$ salts of $O, O$ '-dibenzoyl- and $O, O$ '-di- $p$ toluoyl-( $2 R, 3 R)$-tartaric acid, as well as the acidic and neutral $\mathrm{Mg}^{2+}$ salts of the $O, O^{\prime}$-dibenzoyl-(2R,3R)-tartaric acid could 


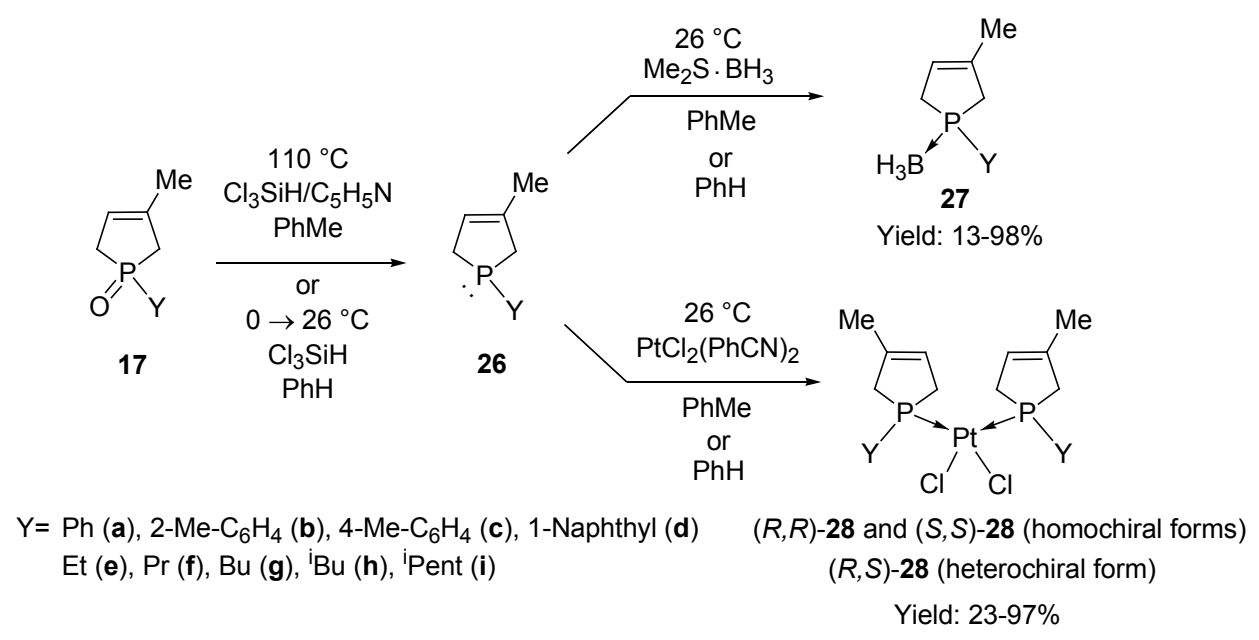

Scheme 14

also be applied as resolving agents for the separation of the enantiomers of 3-phospholene oxides (17). However, in these cases, the success was limited $[68,69,74,75]$.

The above mentioned resolution methods applying TADDOLand tartaric acid derivatives (22-25) may be regarded efficient as, almost in all instances, at least one of the resolving agents (22-25) provided the enantiomers of the 5- and 6-membered $P$-heterocycles (17-21) with an $e e$ above $99 \%$.

The absolute $P$-configurations of the enantiomers of the 3-phospholene oxides (17) were determined by X-ray crystallography and CD spectroscopy $[60,61,67,69,74-76]$. Crystals suitable for X-ray were obtained in the presence of the corresponding resolving agents (22-25) that gave insights into the interactions between the host and guest molecules, and made possible a better understanding of the phenomenon of the molecular recognition.

\subsection{Complexation Reactions of Cyclic Phosphines and Bisphosphines}

P-heterocyclic derivatives are of interest among the P(III)compounds that are used as ligands in transition metal complexes applied as catalysts in homogeneous catalytic reactions. In the last years, the synthesis and catalytic activity of a variety of transition metal complexes incorporating mono- or bidentate 5-, 6- or 7-membered $P$-heterocyles were described [77]. Our research group also studied the synthesis of the platinum complexes with $P$-heterocyclic and bisphosphine ligands $[78,79]$. Many of them were tested as catalysts in the hydroformylation of styrene. In many instances, the borane complexes of the corresponding $P$-heterocycles that may be regarded as the precursors of phosphines, were also synthesized. The phosphines may be liberated from the borane complexes by reaction with secondary amines (e.g. diethylamine) [80].

The 1-aryl- and 1-alkyl-3-phospholene oxides (17a-i) were subjected to deoxygenation by trichlorosilane or with a mixture of trichlorosilane and pyridine, and the 3-phospholenes (26) so obtained were reacted with borane-dimethylsulfide or dichlorodibenzonitrile platinum(II) to afford the corresponding borane- or platinum complexes (27 or $\mathbf{2 8}$ ), respectively. The characteristic ${ }^{1} J_{\mathrm{Pt}-\mathrm{P}}$ couplings in the ${ }^{31} \mathrm{P}$ NMR spectra confirmed that the platinum complexes (28) incorporating the phospholene moieties in position cis were formed exclusively (Scheme 14) $[66,73,78,81,82]$.

The optically active aryl- and alkyl-3-phospholene oxides $((R)-$ or $(S)$-17a-i) obtained by resolution with TADDOL- or tartaric acid derivatives (22-25) were also converted to the corresponding optically active borane- and cis-platinum complexes $\left(27^{*}\right.$ or $\left.\mathbf{2 8}^{*}\right)$ (Fig. 1). It is known that the deoxygenation with trichlorosilane or with a mixture of trichlorosilane and pyridine takes place with retention of the $P$-asymmetric center, so the enantiomeric excess of the optically active borane- and platinum complexes $\left(27^{*}\right.$ or $\left.28^{*}\right)$ was the same, as that in the corresponding starting materials, 3-phospholene oxides $((R)-$ or $(S)-\mathbf{1 7 a - i})$. The stereostructures of the optically active 3-phospholene platinum complexes $\left(\mathbf{2 8}^{*}\right)$ were evaluated by high-level quantum chemical methods $[66,73,78,81,82]$.

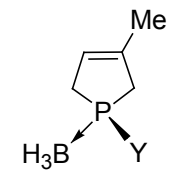

(R)-27* or $(S)-27^{*}$

Yield: $10-91 \%$ ee: $83-99 \%$

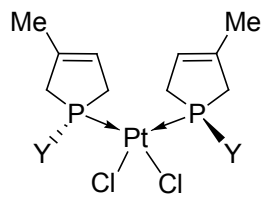

$(R, R)-28^{*}$ or $(S, S)-28^{*}$

Yield: $53-92 \%$ ee: $83-99 \%$

Fig. 1 The optically active 3-phospholene-borane- and 3-phospholeneplatinum complexes prepared $\left(27^{*}\right.$ and $\left.28^{*}\right)$

Similarly to the 3-phospholene oxides (17a-i), the racemic phenyl- and propyl-phospholane oxides (29a-c), the 5-methyl-4-chloro-1,2,3,6-tetrahydrophosphine oxide (29d) and the 4-dichloromethylene-3,5-dimethyl-1-phenyl- 

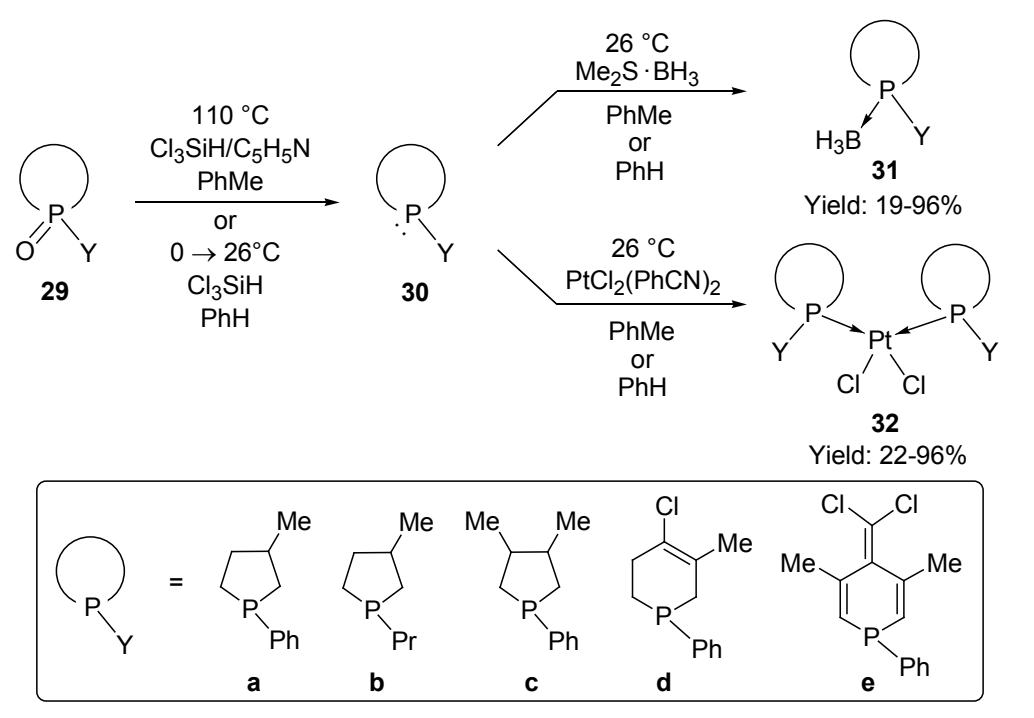

Scheme 15

1,4-dihydrophosphinine oxide (29e) were also converted to the corresponding borane- and cis-platinum complexes (31 and 32) (Scheme 15) [66,78,81].

Recently, our research group investigated and rationalized the possibilities for the deoxygenation of 5-membered $P$-heterocycles, such as phenylphospholene oxides and phenylphospholane oxides (e.g. 17a and 29a) using silanes including the traditional and the more user friendly $\mathrm{Cl}_{3} \mathrm{SiH}, \mathrm{PhSiH}_{3}$, tetramethyldisiloxane and polymethylhydrosiloxane [83].

Bidentate $P$-heterocyclic ligands having exocylic $\mathrm{PPh}_{2}$-functions, such as the 3-diphenylphosphino-1phenylphospholane (33), the 3-diphenylphosphino-1-phenyl1,2,3,6-tetrahydrophosphinine (35) and the 3-diphenylphosphino1-phenyl-1,2,3,4,5,6-hexahydrophosphinine (37) were converted to the corresponding cis-platinum complexes $(\mathbf{3 4}, \mathbf{3 6}$ and $\mathbf{3 8})$, respectively, after double deoxygenation of the corresponding oxides by trichlorosilane (Scheme 16). The relative position of the two P(III)-functions was confirmed by ${ }^{31} \mathrm{P}$ NMR spectral data and quantum chemical calculations [65, 84-88]. It is noteworthy, that the platinum complex of the 3-diphenylphosphino-1-phenyl1,2,3,6-tetrahidrophosphinine $\left(\mathbf{3 6}^{*}\right)$ was also prepared in an optically active form [65].

Several bis(phosphinoxidomethyl)amines (39) obtained by the double Kabachnik-Fields reaction (see Subchapter 1.2) of the corresponding amine, two equivalents of paraformaldehyde and two equivalents of $\mathrm{Ph}_{2} \mathrm{P}(\mathrm{O}) \mathrm{H}$ were subjected to double deoxygenation using phenylsilane. The reaction of bisphosphines (40) so obtained with dichlorodibenzonitrile
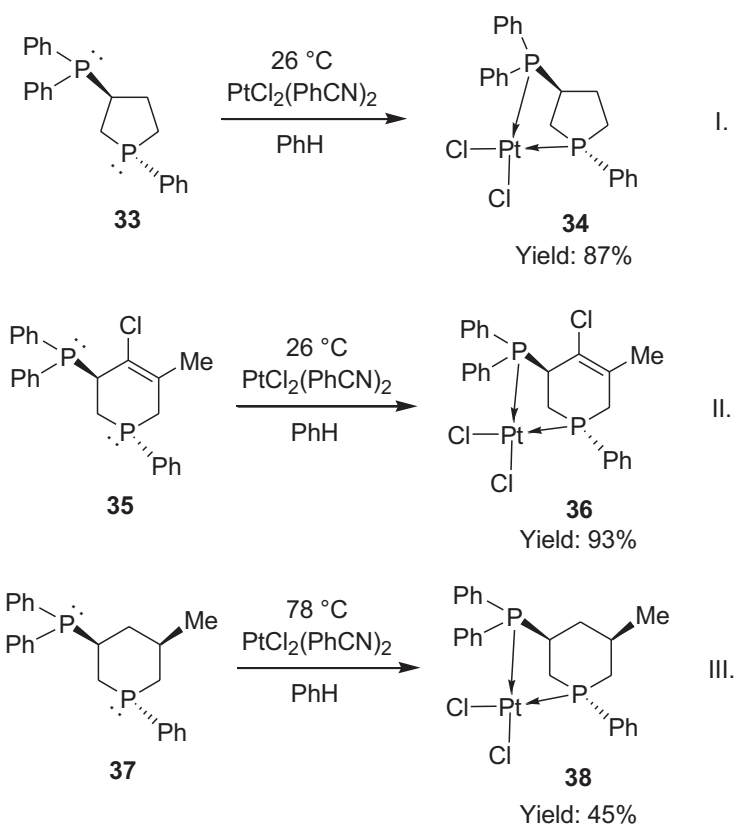

Scheme 16

platinum(II) afforded the corresponding cis-platinum complexes (41) (Scheme 17). The structure of the platinum complexes 41a, 41c and 41f, as well as the intermolecular interactions were investigated by quantum chemical calculations, and X-ray crystallography $[33,34,89]$.

The platinum complexes of the mono- or bidentate $P$-heterocylic ligands $(\mathbf{2 8}, \mathbf{3 2 b}-\mathbf{c}, \mathbf{3 4}, \mathbf{3 6}, \mathbf{3 8}, \mathbf{4 1} \mathrm{c}-\mathrm{d}$ and $\mathbf{4 1 f}-\mathrm{g})$ were tested as catalysts in the hydroformylation of styrene (Scheme 18) $[34,66,73,82,84,90]$. The selectivity of the catalyst is important, as

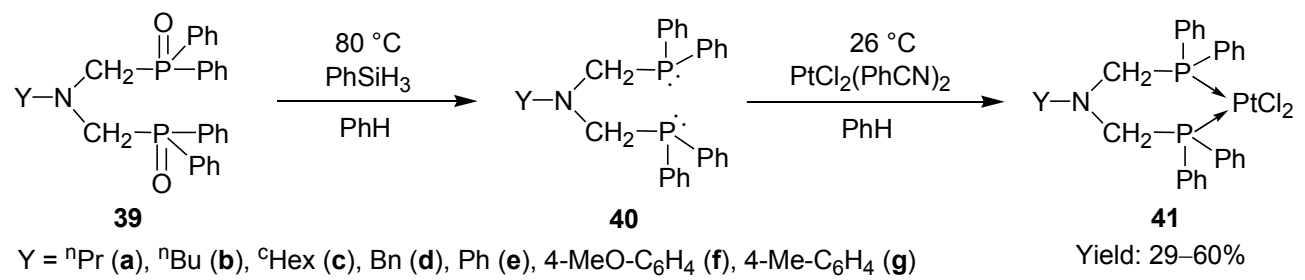

Scheme 17 


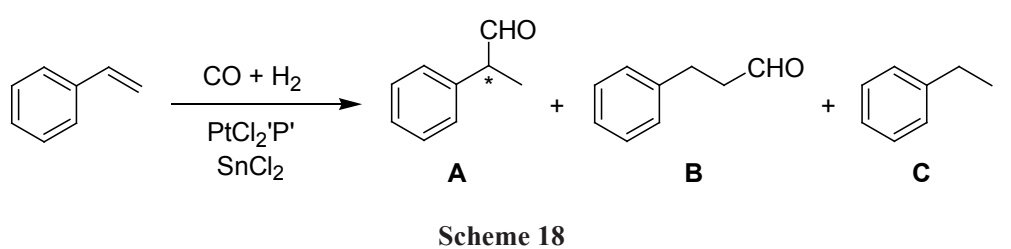

branched and linear aldehyde (A and B), as well as ethylbenzene (C) can be formed in this reaction (Scheme 18).

In most of the cases, an unusual preference for the branched aldehyde was observed that makes our Pt-complexes valuable.

\section{The Synthesis of Dronic Acids/Dronates}

\subsection{Optimization of the Synthesis of}

\section{Dronic Acids/Dronates}

1-Substituted-1-hydroxy-1,1-methylenebisphosphonic acid derivatives (dronic acids or dronates) can be used against various bone diseases. Fig. 2 shows geminal-bisphosphonates (42) and the pyrophosphate analogues (43). The methylene-function of bisphosphonates presents a basis for tailoring the biological and physiological properties through the appendage of $\mathrm{R}^{1}$ and $\mathrm{R}^{2}$ side-chains. In dronic acids and dronates, the $\mathrm{R}^{1}$ group represents a hydroxy substituent. The resulting 1-hydroxy-1,1bisphosphonate arrangement provides a tridentate functionality towards binding $\mathrm{Ca}^{2+}$ ions, and hence promotes the affinity for species responsible for the accumulation of phosphates in the bone tissues [57].

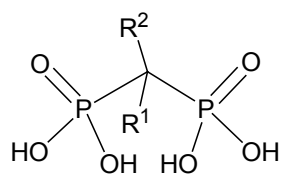

42

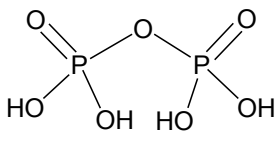

43
Fig. 2 General structures of bisphosphonates and pyrophosphates

The practical synthesis of dronic acids involves the three-component reaction of a substituted carboxylic acid, phosphorous acid and a $P$-chloride, which is usually phosphorus trichloride, and rarely phosphorus oxychloride. The molar ratio of the components applied varied on a broad scale and the solvents applied embrace a wide spectrum including aromatics (chlorobenzene and toluene), 1,4-dioxane, 1,2-dimethoxyethane, PEG-400, n-octane, sulfolane, methanesulfonic acid (MSA) [57].

Regarding the synthesis of zoledronic acid (44), the ratio of imidazolylacetic acid, phosphorous acid and phosphorus trichloride varies significantly as reflected by the $1: 1-5: 2-4.6$ combinations reported. The yields provided are rather variable and move on a broad scale of $24-86 \%$. With lack of purity criteria, the yields may refer to crude mixtures consisting mainly of the dronic acid and its monosodium salt. In the literature, the ratio and the excess of the $P$-reactants has never been explained or commented on. In most cases, inadequate ratios and unnecessary excesses were used in the unoptimized reactions. This resulted in a 'black-box' in respect of the synthesis of dronic acids/dronates. Moreover, a large quantity of hydrochloric acid is formed by hydrolysis of the excess phosphorus trichloride. We were the first who studied, the synthesis of zoledronic and risedronic acids in detail to establish the optimum choice and ratio of the reactants. In addition, we wished to obtain insights into the reaction sequence for the formation of hydroxy-methylenebisphosphonic acids [91].

First, the reaction of imidazolylacetic acid (44), phosphorous acid and phosphorus trichloride leading to zoledronic acid (45a) was studied in MSA at $80{ }^{\circ} \mathrm{C}$ (Scheme 19) [91]. The optimal set of parameters comprised the use of only phosphorus trichloride as the $\mathrm{P}(\mathrm{III})$ species in a quantity of 3.2 equivalents. After completion of the reaction $(3 \mathrm{~h})$, the mixture was hydrolyzed, neutralized and the crude product containing the mixture of zoledronic acid (45a) and its monosodium salt (45a-Na) was recrystallized from aqueous hydrochloric acid to afford pure zoledronic acid (45a) in a yield of $49 \%$ in a purity of $98 \%$.

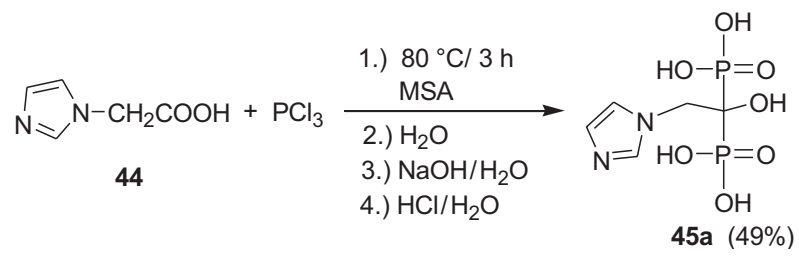

Scheme 19

Similar experiments were carried out for the synthesis of risedronic acid (45b) applying pyridylacetic acid (46) and phosphorus trichloride (Scheme 20.) [91]. In this case, there was no need for a recrystallization at the end. The use of 3.1 equivalents of phosphorus trichloride (again in the absence of phosphorous acid) led to a yield of $74 \%$ of risedronic acid $\mathbf{4 5 b}$.

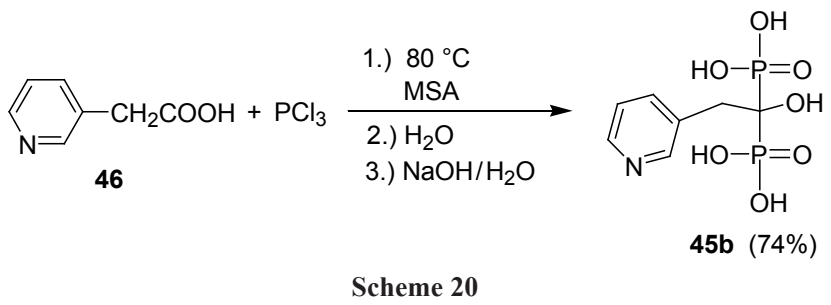

From the above experiments, it is clear that under the conditions applied there is no need to use phosphorous acid in the preparation of dronic acids. At the same time, efficient syntheses require the presence of 3.2 equivalents of phosphorus trichloride. This may mean that phosphorous acid may have 


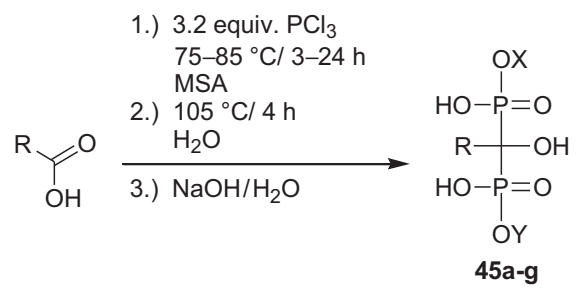

\begin{tabular}{|c|c|c|c|c|c|c|}
\hline Dronate (45) & $\mathbf{R}$ & $\mathbf{X}$ & $\mathbf{Y}$ & Hydrate & Purity (\%) & Yield (\%) \\
\hline zoledronic acid (a) & & $\mathrm{H}$ & $\mathrm{Na} \rightarrow \mathrm{H}$ & - & 100 & 49 \\
\hline risedronic acid (b) & & $\mathrm{H}$ & $\mathrm{H}$ & $1 \times \mathrm{H}_{2} \mathrm{O}$ & 100 & 74 \\
\hline ibandronate (c) & & $\mathrm{H}$ & $\mathrm{Na}$ & - & 98 & 46 \\
\hline alendronate (d) & & $\mathrm{H}$ & $\mathrm{Na}$ & $3 \times \mathrm{H}_{2} \mathrm{O}$ & 98 & 57 \\
\hline etidronate (e) & $\mathrm{Me}$ & $\mathrm{Na}$ & $\mathrm{Na}$ & - & 90 & 36 \\
\hline fenidronate (f) & & $\mathrm{Na}$ & $\mathrm{Na}$ & - & 100 & 42 \\
\hline pamidronate (g) & & $\mathrm{H}$ & $\mathrm{Na}$ & $2 \times \mathrm{H}_{2} \mathrm{O}$ & 97 & 51 \\
\hline
\end{tabular}

been applied in vain in earlier dronic acid syntheses, and quantities of phosphorus trichloride beyond 3.2 equivalents were unnecessary. The unjustified use of phosphorous acid and the unnecessary excess of phosphorus trichloride results in extra costs and environmental burdens (after the excess phosphorus trichloride was hydrolyzed) [91,92]. On the other hand, when phosphorus trichloride was used in a quantity less than 3 equivalents, the conversions were incomplete causing again extra costs in the production of dronic acids/dronates.

Based on the above reactions, we also elaborated the synthesis of ibandronate (45c) and alendronate (45d) [93]. Etidronate (45e) [94], fenidronate (45f) [95] and pamidronate (45g) [96] were also prepared in this way. The experimental data are summarized in Table 1. It can be seen, that in certain causes the acid, while in the other instances the monoNa salt, or the diNa salt were formed.

\subsection{Mechanistic Considerations on the Formation of Dronic Acids/Dronates}

A possible route for the formation of dronic acids in the reaction of a carboxylic acid with phosphorus trichloride in MSA is shown in Scheme 21. Our idea is that 1 equivalent of the phosphorus trichloride is needed to convert the acid to the corresponding acid chloride (47). In MSA as the solvent, a mixed anhydride $\mathrm{RC}(\mathrm{O}) \mathrm{O}(\mathrm{O})_{2} \mathrm{SMe}(\mathbf{4 8})$ may also be formed from the acid chloride and a molecule of solvent, or in another way. In the second step, the intermediates (acid chloride 47 and anhydride 48) formed are reacted further with the remaining part of the phosphorus trichloride, a step that is followed by hydrolysis and $\mathrm{pH}$ adjustment (Scheme 21) [97].

When sulfolane was used as the solvent in the synthesis of pamidronic acid from $\beta$-alanine (49) instead of MSA, no

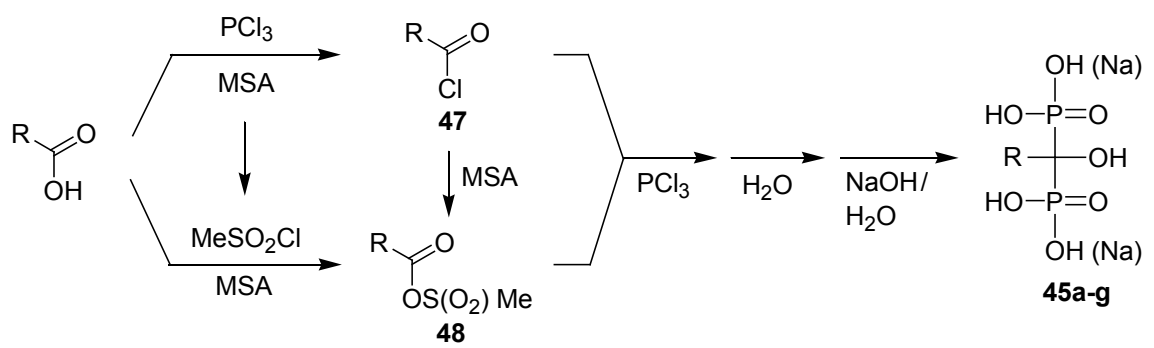

for $\mathrm{R}$, see at Table 1.

Scheme 21 
product was formed, if phosphorus trichloride or phosphorous acid was used alone as $P$-reagent. We had to use phosphorus trichloride and phosphorous acid together in the reaction. The optimal ratio was 2 equivalents of phosphorous acid and 2 equivalents of phosphorus trichloride. In this case, pamidronic acid (45h) was crystallized after the hydrolysis in a yield of $63 \%$, and in a purity of $100 \%$ (Scheme 22) [96].

\begin{tabular}{|c|c|c|c|c|}
\hline \multicolumn{3}{|l|}{$\mathrm{NH}_{2} \mathrm{CH}_{2} \mathrm{CH}_{2} \mathrm{C}$} & $\begin{array}{l}\text { 1.) } 75^{\circ} \mathrm{C} / 12 \mathrm{~h} \\
\text { Sulfolane } \\
\end{array}$ & $\mathrm{HO}-\mathrm{P}=\mathrm{O}$ \\
\hline 49 & 2 equiv. & 2 equiv. & $\begin{array}{ll}\text { 2.) } & 105^{\circ} \mathrm{C} / 3 \mathrm{~h} \\
& \mathrm{H}_{2} \mathrm{O} \\
\text { 3.) } & 0-5{ }^{\circ} \mathrm{C}, 4 \mathrm{~h}\end{array}$ & $\begin{array}{c}\mathrm{HO}-\mathrm{P}=\mathrm{O} \\
\mathrm{OH} \\
45 \mathrm{~h}(63 \%)\end{array}$ \\
\hline
\end{tabular}

Scheme 22

The use of sulfolane as the solvent in the synthesis of other dronic acid/dronates and the mechanism of these reactions are under study. We also investigated the possibility of applying other $P$-reactants.

In summary our minireview may have provided an overview on at least three aspects of "green" chemistry performed in our laboratory, on MW-assisted organophosphorus chemistry, on the synthesis of $P$-ligands and Pt-complexes incorporating them to form potential catalysts, and in the field of optimizing the synthesis of dronic derivatives.

\section{Acknowledgement}

The above project was supported by the Hungarian Scientific and Research Fund (OTKA No. K83118) and by TÁMOP4.2.1/B-09/1/KMR-2010-0002.

\section{References}

[1] Keglevich, G., Sallay, P., Greiner, I. "Continuously operating microwave reactors." Hung. Chem. J. 63. pp. 278-283. 2008.

[2] Loupy, A. (ed.) "Microwaves in Organic Synthesis." Wiley-VCH, Weinheim. 2002.

[3] Kranjc, K., Kocevar, M. "Microwave-Assisted Organic Synthesis: General Considerations and Transformations of Heterocyclic Compounds." Current Organic Chemistry. 14 (10). pp. 1050-1074. 2010. DOI: $10.2174 / 138527210791130488$

[4] Quin, L. D. "A guide to organophosphorus chemistry." New York: Wiley \& Sons. 2000.

[5] Mathey, F. (ed.) "Phosphorus-Carbon Heterocyclic Chemistry: The Rise of a New Domain." Amsterdam: Pergamon. 2001.

[6] Keglevich, G., Grun, A., Hermecz, I., Odinets, I. L. "Quaternary Phosphonium Salt and 1,3-Dialkylimidazolium Hexafluorophosphate Ionic Liquids as Green Chemical Tools in Organic Syntheses." Current Organic Chemistry. 15 (22). pp. 3824-3848. 2011. DOI: $10.2174 / 138527211797884557$

[7] Guenin, E., Meziane, D. "Microwave Assisted Phosphorus Organic Chemistry: A Review." Current Organic Chemistry. 15 (19). pp. 34653485. 2011.

DOI: $10.2174 / 138527211797374724$
[8] Keglevich, G., Grün, A., Bálint, E., Kiss, N. Zs., Kovács, R., Molnár, I. G., Blastik, Zs., Tóth, R. V., Fehérvári, A., Csontos, I." Green Chemical Tools in Organophosphorus Chemistry - Organophosphorus Tools in Green Chemistry." Phosphorus, Sulfur, and Silicon and the Related Elements. 186. pp. 613-620. 2011.

DOI: 10.1080/10426507.2010.507725

[9] Keglevich, G., Kovács, R., Grün, A., Greiner, I. "Environmentally friendly syntheses and tools." Phosphorus, Sulfur, and Silicon and the Related Elements. 188 (1-3). pp. 39-41. 2013.

DOI: $10.1080 / 10426507.2012 .743543$

[10] Keglevich, G., Kerényi, A., Sipos, M., Ujj, V., Makó, A., Csontos, I., Novák, T., Bakó, P., Greiner, I. "Green chemical approaches and tools in the development of environmentally friendly synthetic methods." Periodica Polytechnica Chemical Engineering. 51 (2). pp. 53-56. 2007. DOI: 10.3311/pp.ch.2007-2.08

[11] Keglevich, G. "Editorial (Hot Topic: Special Issue on Microwaveassisted Chemistry)." Current Organic Chemistry. 17 (5). p. 447. 2013. DOI: 10.2174/1385272811317050002

[12] Keglevich, G., Greiner I. "The Meeting of Two Disciplines: Organophosphorus and Green Chemistry." Current Organic Chemistry. 1 (1). pp. 2-16. 2013. DOI: $10.2174 / 221334610101131218094831$

[13] Keglevich, G., Kiss, N. Zs., Mucsi, Z., Jablonkai, E., Bálint, E. "The synthesis of phosphinates - traditional versus green chemical approaches." Green Processing and Synthesis. 3 (2). pp. 103-110. 2014. DOI: 10.1515/gps-2013-0106

[14] Keglevich, G., Novák, T., Vida, L., Greiner, I. "Microwave irradiation as an alternative to phase transfer catalysis in the liquid-solid phase, solvent-free C-alkylation of active methylene containing substrates." Green Chemistry. 8 (12). pp. 1073-1075. 2006. DOI: $10.1039 / \mathrm{b} 610481 \mathrm{a}$

[15] Keglevich, G., Majrik, K., Vida, L., Greiner, I. "Microwave Irradiation as a Green Alternative to Phase Transfer Catalysis: Solid-Liquid Phase Alkylation of Active Methylene Containing Substrates Under SolventFree Conditions." Letters in Organic Chemistry. 5 (3). pp. 224-228. 2008. DOI: $10.2174 / 157017808783955754$

[16] Greiner, I., Grün, A., Ludányi, K., Keglevich, G. "Solid-liquid two-phase alkylation of tetraethyl methylenebisphosphonate under microwave irradiation." Heteroatom Chemistry. 22 (1). pp. 11-14. 2011. DOI: 10.1002/hc.20648

[17] Keglevich, G., Grün, A., Blastik, Zs., Greiner, I. "Solid-liquid phase alkylation of $\mathrm{P}=\mathrm{O}$-functionalized $\mathrm{CH}$ acidic compounds utilizing phase transfer catalysis and microwave irradiation." Heteroatom Chemistry. 22 (2). pp. 174-179. 2011. DOI: $10.1002 / \mathrm{hc} .20673$

[18] Grün, A., Blastik, Zs., Drahos, L., Keglevich, G. "Microwaveassisted alkylation of diethyl ethoxycarbonylmethylphosphonate under solventless conditions." Heteroatom Chemistry. 23 (3). pp. 241-246. 2012

DOI: $10.1002 / \mathrm{hc} .21009$

[19] Grün, A., Blastik, Zs., Drahos, L., Keglevich, G. "Dialkylation of Diethyl Ethoxycarbonylmethylphosphonate under Microwave and Solventless Conditions." Heteroatom Chemistry. 25 (2). pp. 107-113. 2014. DOI: $10.1002 / \mathrm{hc} .21142$

[20] Kukhar, V. P., Hudson, H. R (eds). "Aminophosphonic and Aminophosphinic Acids: Chemistry and Biological Activity." Chichester: Wiley. 2000.

[21] Keglevich, G., Bálint, E. "The Kabachnik-Fields Reaction: Mechanism and Synthetic Use." Molecules. 17 (11). pp. 12821-12835. 2012. DOI: $10.3390 /$ molecules 171112821 
[22] Bhattacharya, A. K., Kaur, T. "An Efficient One-Pot Synthesis of $\alpha$-Amino Phosphonates Catalyzed by Bismuth Nitrate Pentahydrate." Synlett. 5. pp. 745-748. 2007.

DOI: $10.1055 / \mathrm{s}-2007-970762$

[23] Matveeva, E. D., Podrugina, T. A., Tishkovskaya, E. V., Tomilova, L. G., Zefirov, N. S. "A Novel Catalytic Three-Component Synthesis (Kabachnick-Fields Reaction) of $\alpha$-Aminophosphonates from Ketones." Synlett. 15. pp. 2321-2324. 2003.

DOI: $10.1055 / \mathrm{s}-2003-42118$

[24] Lee, S., Park, J. H., Kang, J., Lee, J. K. "Lanthanide triflate-catalyzed three component synthesis of alpha-amino phosphonates in ionic liquids. A catalyst reactivity and reusability study." Chemical Communications. 17. pp. 1698-1699. 2001. DOI: $10.1039 / b 104967 b$

[25] Bhagat, S., Chakraborti, A. K. "An Extremely Efficient ThreeComponent Reaction of Aldehydes/Ketones, Amines, and Phosphites (Kabachnik-Fields Reaction) for the Synthesis of $\alpha$-Aminophosphonates Catalyzed by Magnesium Perchlorate." The Journal of Organic Chemistry. 72 (4). pp. 1263-1270. 2007. DOI: $10.1021 /$ jo062140i

[26] Sun, P., Hu, Z., Huang, Z. "Gallium Triiodide Catalyzed Organic Reaction: A Convenient Synthesis of $\alpha$-Amino Phosphonates." Synthetic Communications. 34 (23). pp. 4293-4299. 2004. DOI: 10.1081/SCC-200039361

[27] Keglevich, G., Szekrenyi, A. "Eco-Friendly Accomplishment of the Extended Kabachnik-Fields Reaction; a Solvent- and Catalyst-Free Microwave-Assisted Synthesis of Alfa-Aminophosphonates and $\alpha$-Aminophosphine Oxides." Letters in Organic Chemistry. 5 (8). pp. 616-622. 2008 DOI: $10.2174 / 157017808786857598$

[28] Prauda, I., Greiner, I., Ludányi, K., Keglevich, G. "Efficient Synthesis of Phosphono- and Phosphinoxidomethylated N-Heterocycles under Solvent-Free Microwave Conditions." Synthetic Communications. 37 (2). pp. 317-322. 2007

DOI: $10.1080 / 00397910601033856$

[29] Keglevich, G., Szekrényi, A., Sipos, M., Ludányi, K., Greiner, I. "Synthesis of cyclic aminomethylphosphonates and aminomethylarylphosphinic acids by an efficient microwave-mediated phosphaMannich approach." Heteroatom Chemistry. 19 (2). pp. 207-210. 2008. DOI: 10.1002/hc.20387

[30] Bálint, E., Takács, J., Drahos, L., Juranovič, A., Kočevar, M., Keglevich, G. " $\alpha$-Aminophosphonates and $\alpha$-Aminophosphine Oxides by Microwave-Assisted Kabachnik-Fields Reactions of 3-Amino-6-methyl-2Hpyran-2-ones." Heteroatom Chemistry. 24 (3). pp. 221-225. 2013. DOI: $10.1002 /$ hc. 21086

[31] Bálint, E., Fazekas, E., Takács, J., Tajti, Á., Juranovič, A., Kočevar, M., Keglevich, G. "Microwave-Assisted Synthesis of Organophosphorus Compounds. Phosphorus." Sulfur, and Silicon and the Related Elements. 188 (1-3). pp. 48-50. 2013.

DOI: $10.1080 / 10426507.2012 .743544$

[32] Keglevich, G. Szekrényi, A., Szöllősy, Á., Drahos, L. "Synthesis of Bis(phosphonatomethyl)-, Bis(phosphinatomethyl)-, and Bis(phosphinoxidomethyl)amines, as Well as Related Ring Bis(phosphine) Platinum Complexes." Synthetic Communications. 41 (15). pp. 2265-2272. 2011. DOI: $10.1080 / 00397911.2010 .501478$

[33] Bálint, E., Fazekas, E., Pintér, G., Szollosy, A., Holczbauer, T., Czugler, M., Drahos, L., Körtvélyesi, T., Keglevich, G. "Synthesis and Utilization of the $\mathrm{Bis}(>\mathrm{P}(\mathrm{O}) \mathrm{CH} 2)$ amine Derivatives Obtained by the Double Kabachnik-Fields Reaction with Cyclohexylamine; Quantum
Chemical and X-Ray Study of the Related Bidentate Chelate Platinum Complexes." Current Organic Chemistry. 16 (4). pp. 547-554. 2012. DOI: $10.2174 / 138527212799499822$

[34] Bálint, E., Fazekas, E., Pongrácz, P., Kollár, L., Drahos, L., Holczbauer, T., Czugler, M., Keglevich, G. "N-benzyl and $N$-aryl bis(phospha-Mannich adducts): Synthesis and catalytic activity of the related bidentate chelate platinum complexes in hydroformylation." Journal of Organometallic Chemistry. 717. pp. 75-82. 2012. DOI: 10.1016/j.jorganchem.2012.07.031

[35] Jablonkai, E., Keglevich, G. "P-C bond formation by coupling reaction utilizing $>\mathrm{P}(\mathrm{O}) \mathrm{H}$ species as the reagents." Current Organic Synthesis. 11 (3). pp. 429-453. 2014. DOI: $10.2174 / 15701794113109990066$

[36] Jablonkai, E., Keglevich, G. "Advances and New Variations of the Hirao Reaction." Organic Preparations and Procedures International. 46 (4). pp. 281-316. 2014. DOI: $10.1080 / 00304948.2014 .922376$

[37] Jablonkai, E., Keglevich, G. "P-Ligand-free, microwave-assisted variation of the Hirao reaction under solvent-free conditions; the $\mathrm{P}-\mathrm{C}$ coupling reaction of $>\mathrm{P}(\mathrm{O}) \mathrm{H}$ species and bromoarenes." Tetrahedron Letters. 54 (32). pp. 4185-4188. 2013. DOI: $10.1016 /$ j.tetlet.2013.05.111

[38] Keglevich, G., Grün, A., Bölcskei, A., Drahos, L., Kraszni, M., Balogh, G. T. "Synthesis and Proton Dissociation Properties of Arylphosphonates; A Microwave-Assisted Catalytic Arbuzov Reaction with Aryl Bromides." Heteroatom Chemistry. 23 (6). pp. 574-582. 2012. DOI: $10.1002 /$ hc. 21053

[39] Keglevich, G., Bálint, E., Karsai, É., Grün, A., Bálint, M., Greiner, I. "Chemoselectivity in the microwave-assisted solvent-free solid-liquid phase benzylation of phenols: O- versus C-alkylation." Tetrahedron Letters. 49 (34). pp. 5039-5042. 2008. DOI: $10.1016 /$ j.tetlet.2008.06.051

[40] Bálint, E., Greiner, I., Keglevich, G. "Microwave-Assisted Alkylation of Phenols by Quaternary Onium Salts." Letters in Organic Chemistry. 8 (1). pp. 22-27. 2011. DOI: $10.2174 / 157017811794557822$

[41] Hohmann, E., Keglevich, G., Greiner, I. "The Effect of Onium Salt Additives on the Diels Alder Reactions of a 1-Phenyl1,2-dihydrophosphinine Oxide under Microwave Conditions." Phosphorus, Sulfur, and Silicon and the Related Elements. 182 (10) pp. 2351-2357. 2008. DOI: $10.1080 / 10426500701441473$

[42] Bálint, E., Jablonkai, E., Bálint, M., Keglevich, G. "Alkylating esterification of 1-hydroxy-3-phospholene oxides under solventless MW conditions." Heteroatom Chemistry. 21 (4). pp. 211-214. 2010. DOI: $10.1002 /$ hc.20596

[43] Keglevich, G., Balint, E., Kiss, N. Zs., Jablonkai, E., Hegedus, L., Grun, A., Greiner, I. "Microwave-Assisted Esterification of Phosphinic Acids." Current Organic Chemistry. 15 (11). pp. 1802-1810. 2011. DOI: $10.2174 / 138527211795656570$

[44] Keglevich, G., Dudás, E., Sipos, M., Lengyel, D., Ludányi, K. "Efficient synthesis of cyclic $\beta$-oxophosphoranes by the microwave-assisted reaction of cyclic phosphine oxides and dialkyl acetylenedicarboxylate." Synthesis. (8). pp. 1365-1369. 2006. DOI: $10.1055 / \mathrm{s}-2006-929395$

[45] Keglevich, G., Forintos, H., Körtvélyesi, T. "Synthesis and Reactions of $\beta$-Oxophosphoranes/Ylides Containing a Cyclic or Acyclic P-Moiety." Current Organic Chemistry. 8 (13). pp. 1245-1261. 2004. DOI: $10.2174 / 1385272043370023$ 
[46] Kiss, N. Z., Ludányi, K., Drahos, L., Keglevich, G. "Novel Synthesis of Phosphinates by the Microwave-Assisted Esterification of Phosphinic Acids." Synthetic Communications. 39 (13). pp. 2392-2404. 2009. DOI: 10.1080/00397910802654880

[47] Keglevich, G., Kiss, N. Zs., Mucsi, Z., Körtvélyesi, T. "Insights into a surprising reaction: The microwave-assisted direct esterification of phosphinic acids." Organic \& Biomolecular Chemistry. 10 (10). pp. 2011-2018. 2012.

DOI: $10.1039 / \mathrm{c} 2 \mathrm{ob} 06972 \mathrm{e}$

[48] Kiss, N. Z., Böttger, É., Drahos, L., Keglevich, G. "MicrowaveAssisted Direct Esterification of Cyclic Phosphinic Acids." Heteroatom Chemistry. 24 (4). pp. 283-288. 2013.

DOI: $10.1002 / \mathrm{hc} .21092$

[49] Keglevich, G., Kiss, N. Z., Drahos, L., Körtvélyesi, T. "Direct esterification of phosphinic acids under microwave conditions: Extension to the synthesis of thiophosphinates and new mechanistic insights." Tetrahedron Letters. 54 (6). pp. 466-469. 2013. DOI: 10.1016/j.tetlet.2012.11.054

[50] Keglevich, G., Kiss, N. Z., Körtvélyesi, T. "Microwave-Assisted Functionalization of Phosphinic Acids: Amidations Versus Esterifications." Heteroatom Chemistry. 24 (2). pp. 91-99. 2013. DOI: $10.1002 / \mathrm{hc} .21068$

[51] Kiss, N. Z., Simon, A., Drahos, L., Huben, K., Jankowski, S., Keglevich, G. "Synthesis of 1-amino-2,5-dihydro-1H-phosphole 1-oxides and their N-phosphinoyl derivatives, bis(2,5-dihydro-1H-phoshol-1-yl) amine P,P'-dioxides." Synthesis. 45 (2). pp. 199-204. 2013 DOI: $10.1055 / \mathrm{s}-0032-1316830$

[52] Keglevich, G., Dudás, E. "Microwave-Promoted Efficient Synthesis of 2-Phosphabicyclo[2.2.2] octadiene- and Octene-2-oxides under Solvent-Free Conditions in Diels-Alder Reaction." Synthetic Communication. 37 (18). pp. 3191-3199. 2007. DOI: $10.1080 / 00397910701547532$

[53] Keglevich, G., Kovács, R., Drahos, L. "Diels-Alder Cycloadditions of 1,2-Dihydrophosphinine Oxides and Fragmentation-Related Phosphorylations with 2-Phosphabicyclo[2.2.2]Octadiene Oxides Under Green Chemical Conditions-The Role of Microwave and Ionic Liquids." Phosphorus, Sulfur, and Silicon and the Related Elements. 186 (11). pp. 2172-2179. 2011.

DOI: $10.1080 / 10426507.2011 .597807$

[54] Keglevich, G., Tóth, V. R., Drahos, L. "Microwave-assisted synthesis of a-hydroxy-benzylphosphonates and -benzylphosphine oxides." Heteroatom Chemistry. 22 (1). pp. 15-17. 2011.

DOI: $10.1002 / \mathrm{hc} .20649$

[55] Grün, A., Molnár, I. G., Bertók, B., Greiner, I., Keglevich, G. "Synthesis of $\alpha$-hydroxy-methylenebisphosphonates by the microwave-assisted reaction of $\alpha$-oxophosphonates and dialkyl phosphites under solventless conditions." Heteroatom Chemistry. 20 (6). pp. 350-354. 2009.

DOI: $10.1002 / \mathrm{hc} .20558$

[56] Keglevich, G., Grün, A., Molnár, I. G., Greiner, I. "Phenyl-, benzyland unsymmetrical hydroxy-methylenebisphosphonates as dronic acid ester analogues from a-oxophosphonates by microwave-assisted synthesis." Heteroatom Chemistry. 22 (5). pp. 640-648. 2011. DOI: $10.1002 / \mathrm{hc} .20727$

[57] Hudson, H. R., Wardle, N. J., Bligh, S. W. A., Greiner, I., Grun, A., Keglevich, G. "N-Heterocyclic Dronic Acids: Applications and Synthesis." Mini-Reviews in Medicinal Chemistry. 12 (4). pp. 313325. 2012.

DOI: $10.2174 / 138955712799829285$

[58] Noyori, R. "Asymmetric Catalysis in Organic Synthesis." New York: John Wiley \& Sons. 1994.
[59] Imamoto, T. "Optically active phosphorus compounds." In: Engel, R. (ed). Handbook of Organophosphorus Chemistry. New York: Marcel Dekker. 1992.

[60] Novák, T., Schindler, J., Ujj, V., Czugler, M., Fogassy, E., Keglevich, G. "Resolution of 3-methyl-3-phospholene 1-oxides by molecular complex formation with TADDOL derivatives." Tetrahedron: Asymmetry. 17 (18). pp. 2599-2602. 2006.

DOI: $10.1016 /$ j.tetasy.2006.09.016

[61] Novák, T., Ujj, V., Schindler, J., Czugler, M., Kubinyi, M., Mayer, Zs. A., Fogassy, E., Keglevich, G. "Resolution of 1-substituted-3methyl-3-phospholene 1-oxides by molecular complex formation with TADDOL derivatives." Tetrahedron: Asymmetry. 18 (24). pp. 29652972. 2007.

DOI: $10.1016 /$ j.tetasy.2007.11.028

[62] Novák, T., Schindler, J., Ujj, V., Czugler, M., Fogassy, E., Keglevich, G. "Chiral P-Heterocycles: Efficient Method for the Resolution of 3-methyl-3-phospholene 1-oxides." Phosphorus, Sulfur, and Silicon and the Related Elements. 183 (2-3). pp. 543-546. 2008. DOI: $10.1080 / 10426500701764890$

[63] Ujj, V., Szuhánszki, T., Schinder, J., Czugler, M., Fogassy, E., Keglevich, G. "Separation of the enantiomers of P-chiral cyclic phosphorous compounds." Hungarian Journal of Industrial Chemistry 36 (1-2). pp. 131-136. 2008.

[64] Keglevich, G., Dvorszki, J., Ujj, V., Ludányi, K. "The synthesis of optically active P-heterocycles." Heteroatom Chemistry. 21 (4). pp. 271-277. 2010

DOI: $10.1002 / \mathrm{hc} .20599$

[65] Ujj, V., Kerenyi, A., Laki, A., Fogassy, E., Keglevich, G. "Optically Active 6-Membered P-Heterocycles: 1-Phenyl-1,2Dihydrophosphinine Oxide and 1-Phenyl-3-Diphenylphosphinoyl1,2,3,6-Tetrahydrophosphinine Oxide." Letters in Organic Chemistry. 7 (2). pp. 110-113. 2010. DOI: $10.2174 / 157017810790796345$

[66] Keglevich, G., Bagi, P., Szöllősy, Á., Körtvélyesi, T., Pongrácz, P., Kollár, L., Drahos, L. "Platinum(II) complexes incorporating racemic and optically active 1-alkyl-3-phospholenes and 1-propylphospholane P-ligands: Synthesis, stereostructure, NMR properties and catalytic activity." Journal of Organometallic Chemistry. 696 (22). pp. 3557-3563. 2011.

DOI: 10.1016/j.jorganchem.2011.08.006

[67] Ujj, V., Schindler, J., Novák, T., Czugler, M., Fogassy, E., Keglevich, G. "Coordinative resolution of 1-phenyl- and 1-naphthyl-3-methyl3-phospholene 1-oxides with calcium hydrogen O,O'-dibenzoyl(2R,3R)-tartrate or calcium hydrogen O,O'-di-p-toluyl-(2R,3R)tartrate." Tetrahedron: Asymmetry. 19 (16). pp. 1973-1977. 2008. DOI: $10.1016 /$ j.tetasy.2008.07.029

[68] László, K. (ed.) "Conference of Msc students - Abstracts of the best contributions October 2008." Periodica Polytechnica Chemical Engineering. 53 (1). pp.19-27. 2009. DOI: $10.3311 /$ pp.ch.2009-1.04

[69] Ujj, V., Bagi, P., Schindler, J., Madarász, J., Fogassy, E., Keglevich, G. "A practical and efficient method for the resolution of 3-phospholene 1-oxides via coordination complex formation." Chirality. 22 (7). pp. 699-705. 2010. DOI: $10.1002 /$ chir.20821

[70] Ujj, V., Bagi, P., Laki, A., Fogassy, E., Keglevich, G. "Resolution of P-Heterocycles with Tartaric Acid Derivatives." Phosphorus, Sulfur, and Silicon and the Related Elements. 186 (4). pp. 792-793. 2011. DOI: $10.1080 / 10426507.2010 .497520$ 
[71] Bagi, P., Laki, A., Keglevich, G. "Preparation of Optically Active Six-Membered P-Heterocycles: A 3-Phosphabicyclo[3.1.0] hexane 3-oxide, a 1,2-Dihydrophosphinine 1-oxide, and a 1,2,3,6-Tetrahydrophosphinine 1-oxide." Heteroatom Chemistry. 24 (3). pp. 179-186. 2013.

DOI: $10.1002 / \mathrm{hc} .21080$

[72] Bagi, P., Kovács, T., Laki, A., Fekete, A., Fogassy, E., Keglevich, G. "Resolution of 5- and 6-Membered P-Heterocycles: Racemic and Optically Active Platinum(II)-3-Phospholene Complexes." Phosphorus, Sulfur, and Silicon and the Related Elements. 188 (1-3). pp. 36-38. 2013. DOI: 10.1080/10426507.2012.743545

[73] Bagi, P., Kovács, T., Szilvási, T., Pongrácz, P., Kollár, L., Drahos, L., Fogassy, E., Keglevich, G. "Platinum(II) complexes incorporating racemic and optically active 1-alkyl-3-phospholene P-ligands: Synthesis, stereostructure, NMR properties and catalytic activity." Journal of Organometallic Chemistry. 751. pp. 306-313. 2014. DOI: 10.1016/j.jorganchem.2013.03.045

[74] Bagi, P., Fekete, A., Kállay, M., Hessz, D., Kubinyi, M., Holczbauer, T., Czugler, M., Fogassy, E., Keglevich, G. "Resolution of 1-n-Butyl3-Methyl-3-Phospholene 1-Oxide With TADDOL Derivatives and Calcium Salts of O,O'-Dibenzoyl-(2R,3R)- or O,O'-di-p-Toluoyl(2R,3R)-tartaric Acid." Chirality. 26 (3). pp. 174-182. 2014 DOI: 10.1002/chir.22293

[75] Bagi, P., Kállay, M., Hessz, D., Kubinyi, M., Holczbauer, T., Czugler, M., Fogassy, E., Keglevich, G. "Resolution of 1-n-propoxy-3-methyl3-phospholene 1-oxide by diastereomeric complex formation using TADDOL derivatives and calcium salts of $\mathrm{O}, \mathrm{O}^{\prime}$-dibenzoyl-(2R,3R)or O,O'-di-p-toluoyl-(2R,3R)-tartaric acid." Tetrahedron: Asymmetry. 25 (4). pp. 318-326. 2014.

DOI: $10.1016 /$ j.tetasy.2014.01.002

[76] Mayer, Zs. A., Kállay, M., Kubinyi, M., Keglevich, G., Ujj, V., Fogassy, E. "Assignment of absolute configurations of chiral phospholene oxides by UV/CD spectroscopy using TD-DFT quantum chemical calculations and singular value decomposition approach for the analysis of the spectra." Journal of Molecular Structure: THEOCHEM. 906 (1-3). pp. 94-99. 2009.

DOI: 10.1016/j.theochem.2009.04.004

[77] Kollár, L., Keglevich, G. "P-Heterocycles as Ligands in Homogeneous Catalytic Reactions." Chemical Reviews. 110 (7). pp. 4257-4302. DOI: $10.1021 / \mathrm{cr} 900364 \mathrm{c}$

[78] Keglevich, G., Kollár, L. "Platinum Complexes of Five- and SixMembered P-Heterocycles as Potential Catalysts." Letters in Organic Chemistry. 7 (8) pp. 612-620. 2010. DOI: $10.2174 / 157017810793811713$

[79] Keglevich, G., Bagi, P., Bálint, E., Körtvélyesi, T. "The synthesis of platinum complexes of cyclic phoshines and bisphosphines." In: Varennikov, L., Yedemsky, E. (eds). Platinum: Compounds, Production and Applications. New York: Nova Science Publishers. pp. 83-102. 2013.

[80] Gourdel, Y., Ghanimi, A., Pellon, P., Le Corre, M. "Activation of phosphines with borane." Tetrahedron Letters. 34 (6). pp. 1011-1012. 1993.

DOI: 10.1016/s0040-4039(00)77478-8

[81] Kerényi, A., Kovács, V., Körtvélyesi, T., Ludányi, K., Drahos, L., Keglevich, G. "A new family of platinum(II) complexes incorporating five- and six-membered cyclic phosphine ligands." Heteroatom Chemistry. 21 (2). pp. 63-70. 2010.

DOI: $10.1002 / \mathrm{hc} .20579$
[82] Bagi, P., Kovács, T., Szilvási, T., Pongrácz, P., Kollár, L., Drahos, L., Fogassy, E., Keglevich, G. "Platinum(II) complexes incorporating racemic and optically active 1-aryl-3-phospholene P-ligands; Synthesis, stereostructure, NMR properties and catalytic activity." Journal of Organometallic Chemistry. 751. pp. 306-313. 2014. DOI: 10.1016/j.jorganchem.2013.03.045

[83] Keglevich, G., Kovacs, T. "Silanes as reagents for the deoxygenation of tertiary phosphine oxides - a case study for the deoxygenation of 5-membered cyclic phosphine oxides." Current Green Chemistry. 1 (2). pp. 182-188. 2014. DOI: $10.2174 / 2213346101666140115214100$

[84] Petrusiewicz, K. M., Flis, A., Ujj, V., Körtvélyesi, T., Drahos, L., Pongrácz, P., Kollár, L., Keglevich, G. "Synthesis and use of borane and platinum(II) complexes of 3-diphenylphosphino-1- phenylphospholane (LuPhos)." Heteroatom Chemistry. 22 (6). pp. 730-736. 2011. DOI: $10.1002 / \mathrm{hc} .20741$

[85] Keglevich, G., Sipos, M., Szieberth, D. Nyulászi, L., Imre, T., Ludányi, K., Tőke, L. "Weak intramolecular interactions as controlling factors in the diastereoselective formation of 3-phosphinoxido- and 3-phosphono-1,2,3,6-tetrahydrophosphinine 1-oxides." Tetrahedron. 60 (31). pp. 6619-6627. 2004. DOI: $10.1016 /$ j.tet.2004.05.090

[86] Keglevich, G., Sipos, M., Szieberth, D., Petőcz, G., Kollár, L. "4-Chloro-5-methyl-3-diphenylphosphino-1-phenyl-1,2,3,6tetrahydrophosphinine as a bidentate P-ligand in a cis chelate Pt(II) complex." Journal of Organometallic Chemistry. 689 (20). pp. 31583162. 2004.

DOI: 10.1016/j.jorganchem.2004.06.062

[87] Keglevich, G., Sipos, M., Körtvélyesi, T., Imre, T., Töke, L. "1,2,3,4,5,6-Hexahydrophosphinine 1-oxides with an exocyclic P-function at position 3: diastereoselective synthesis, stereostructure and conformation." Tetrahedron Letters. 46 (10). pp. 1655-1658. 2005. DOI: $10.1016 /$ j.tetlet.2005.01.073

[88] Keglevich, G., Sipos, M., Ujj, V., Körtvélyesi, T. "Diastereoselective Synthesis of 3-Phosphinoxido- and 3-Phosphono-1,2,3,4,5,6Hexahydrophosphinine Oxides as Potential Precursors of Bidentate P-Ligands." Letters in Organic Chemistry. 2 (7). pp. 608-612. 2005. DOI: 10.2174/157017805774296993

[89] Keglevich, G., Szekrényi, A., Szöllősy, Á., Drahos, L. "Synthesis of Bis(phosphonatomethyl)-, Bis(phosphinatomethyl)-, and Bis(phosphinoxidomethyl)amines, as Well as Related Ring Bis(phosphine) Platinum Complexes." Synthetic Communications. 41 (15). pp. 2265-2272. 2011. DOI: $10.1080 / 00397911.2010 .501478$

[90] Pongrácz, P., Kollár, L., Kerényi, A., Kovács, V., Ujj, V., Keglevich, G. "Hydroformylation of styrene in the presence of platinum(II) complex catalysts incorporating cyclic phosphines and phosphonous diesters as P-ligands." Journal of Organometallic Chemistry. 696 (10). pp. 2234-2237. 2011.

DOI: 10.1016/j.jorganchem.2010.11.045

[91] Keglevich, G., Grün, A., Aradi, K., Garadnay, S., Greiner, I. "Optimized synthesis of $N$-heterocyclic dronic acids; closing a blackbox era." Tetrahedron Letters. 52 (21). pp. 2744-2746. 2011. DOI: 10.1016/j.tetlet.2011.03.093

[92] Garadnay, S., Grün, A., Keglevich, G., Neu, J. "Novel process for the preparation of dronic acids." WO2012107787 Chemical Abstracts. 157. 356874. 2012.

[93] Keglevich, G., Grün, A., Kovács, R., Garadnay, S., Greiner, I. "Rational synthesis of Ibandronate and Alendronate." Current Organic Synthesis. 10 (4). pp. 640-644. 2013. 
[94] Kovács, R., Nagy, D. I., Grün, A., Balogh, G. T., Garadnay, S., Greiner, I., Keglevich, G. "Optimized Synthesis of Etidronate." Letters in Drug Design \& Discovery. 10 (8). pp. 733-737. 2013.

DOI: $10.2174 / 15701808113109990026$

[95] Grün, A., Kovács, R., Nagy, D. I., Garadnay, S., Greiner, I., Keglevich, G. "The Rational Synthesis of Fenidronate." Letters in Organic Chemistry. 11 (5). pp. 368-373. 2014.

DOI: $10.2174 / 1570178611666140124001516$
[96] Kovács, R., Grün, A., Németh, O., Garadnay, S., Greiner, I., Keglevich, G. "The Synthesis of Pamidronic Derivatives in Different Solvents: An Optimization and a Mechanistic Study." Heteroatom Chemistry. 25 (3). pp. 186-193. 2014.

[97] Keglevich, G., Grün, A., Kovacs, R., Koos, K., Szolnoki, B., Garadnay, S., Neu, J., Drahos, L., Greiner, I. "Heteroarylacetyl chlorides and mixed anhydrides as intermediates in the synthesis of heterocyclic dronic acids." Letters in Drug Design \& Discovery. 9 (4). pp. 345-351. 2012.

DOI: $10.2174 / 157018012799859963$ 